\title{
Review \\ Energy Management Strategy for Plug-In Hybrid Electric Vehicles Based on Driving Condition Recognition: A Review
}

\author{
Chunna Liu and Yan Liu* (D) \\ School of Mechanical Engineering, Shandong University, No. 73 Jingshi Road, Jinan 250061, China; \\ chunnal@mail.sdu.edu.cn \\ * Correspondence: liuyan_2006@sdu.edu.cn
}

check for updates

Citation: Liu, C.; Liu, Y. Energy Management Strategy for Plug-In Hybrid Electric Vehicles Based on Driving Condition Recognition: A Review. Electronics 2022, 11, 342. https://doi.org/10.3390/ electronics 11030342

Academic Editor: Gianpaolo Vitale

Received: 27 December 2021

Accepted: 20 January 2022

Published: 23 January 2022

Publisher's Note: MDPI stays neutral with regard to jurisdictional claims in published maps and institutional affiliations.

Copyright: (C) 2022 by the authors. Licensee MDPI, Basel, Switzerland. This article is an open access article distributed under the terms and conditions of the Creative Commons Attribution (CC BY) license (https:// creativecommons.org/licenses/by/ $4.0 /)$.

\begin{abstract}
Appropriate energy management strategies (EMSs) have been selected for plug-in hybrid electric vehicles (PHEVs) based on driving-condition recognition (DCR) according to the acquired driving information, so as to minimize the target parameters. With online control and offline optimization, the strategy is suitable for real-time applications and is of great significance to repetitive routes, owing to its simplicity and ease of implementation. This paper aims to identity the DCR-based EMSs, develop efficient EMSs, and invite researchers involved in this field to discover new solutions. This paper presents a comprehensive analysis of EMSs based on DCR in terms of principles, the scope of application as well as their advantages and disadvantages, and provides a thorough survey of the latest progress in EMSs. We concluded that DCR-based EMSs show an improvement in energy saving and the pollutant-discharging effect.
\end{abstract}

Keywords: PHEV; EMS; DCR

\section{Introduction}

PHEVs, which are transition vehicles between conventional vehicles and electric vehicles, possess great potential in real-life cycles. There is a larger margin of efficiency improvement from conventional vehicles to PHEVs, which could also compensate for the technical shortcomings of fuel cells. As vehicles powered by at least two power sources, PHEVs usually involve an internal combustion engine and an electric motor, with external power supplies. There are different intrinsic characteristics between an engine and electric motor, such as frequency response characteristics, torque characteristics and working efficiency. Therefore, it is difficult to collocate two power sources to meet the requirements for vehicle performance and energy economy and to keep the state of charge (SOC) at no less than the pre-set value through online implementation. All the above mentioned problems should be addressed by EMSs.

According to the control methods, EMSs can be classified into two categories. The EMS framework is illustrated in Figure 1. Deterministic rule-based strategies were first applied to the energy management of PHEVs. Banvait et al. [1] detailed a charge depletioncharge sustaining (CD-CS) strategy instead of the original electric assistance strategy. The speed-switching power, following the auxiliary power unit cooperative control strategy, which is forced on the runs along with the optimal brake specific fuel consumption obtain good curve, was presented by Shen et al. [2]. Fuzzy logic belongs to intelligent control methods, dispenses with accurate mathematical models of controlled systems, possesses a self-learning ability, as well as high adaptivity and robustness. So, it is widely utilized in complex nonlinear problems [3-5]. Denis et al. [6] designed a Sugeno-type fuzzy logic controller by taking the moving average of the past speed and the current global discharge rate as the inputs so as to benefit from the trip information. Likewise, an adaptive-equivalent consumption minimization strategy blending a fuzzy inference system to improve the self-adaptation was provided by Li et al. [7]. For the fulfillment 
of global optimization, various algorithms have emerged. The main optimization algorithms encompass dynamic programming (DP) [8-10], Pontryagin's minimum principle (PMP), stochastic dynamic programming (SDP), genetic algorithm (GA), particle swarm optimization (PSO), and an aerodynamic traffic flow model. Gong et al. [11] developed a two-stage dynamic programming algorithm, which could improve computational efficiency and fuel economy, with the historical and real-time traffic-flow parameter detection system. Du et al. [12] optimized the logic-threshold value of the rule-based EMS using the improved Non-dominated Sorting Genetic Algorithm-II (NSGA-II) to obtain the optimal logic threshold value. Real-time optimization-based EMSs mainly refer to equivalent consumption-minimization strategies (ECMSs) [13-15] and improved ECMSs. An adaptive, simplified EC MS-based strategy was detailed by Zeng et al. to reduce calculation load [16]. A real-time control, based on DP-ECMS, was proposed by Wang et al. to achieve the suboptimal solution [17]. Model Predictive Control (MPC), a feedback control method belonging to local optimization-based EMSs, compensates for the lack of online application of the global optimization-based EMSs [18]. Lin et al. [14] modelled the power demand from the driver as a random Markov process. Then, the optimal control strategy was obtained by SDP. A novel hierarchical-control framework was addressed by Zhang et al. to achieve the instantaneous vehicle-environment cooperative control [15].

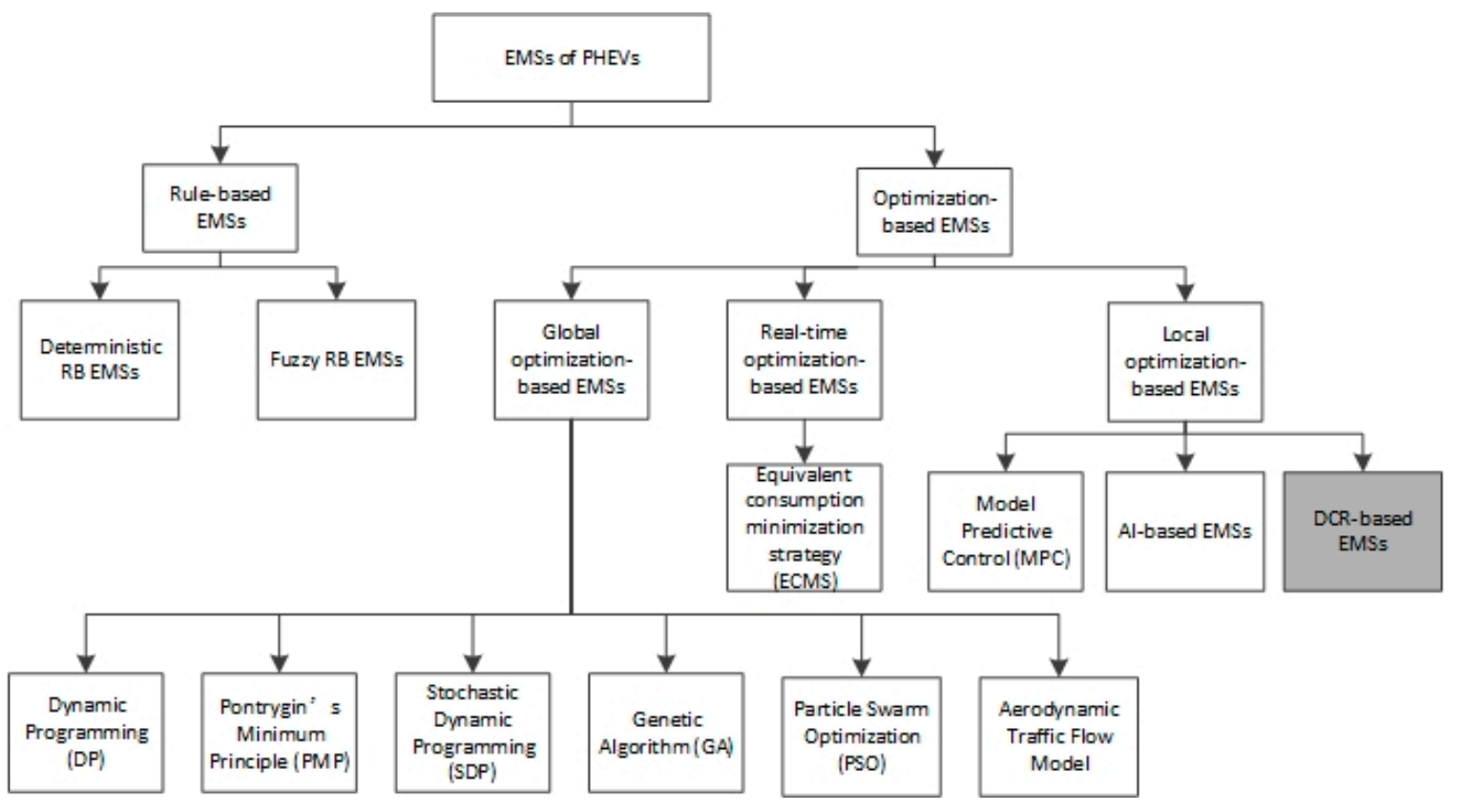

Figure 1. The framework of EMSs.

With the development of computer science and technology, artificial intelligence (AI) is increasingly used in the energy management of PHEVs. Widely used AI technologies include Artificial Neural Networks (ANN), deep learning [19], deep reinforcement learning [20], etc. Xie et al. [21] proposed a data-driven ECMS that determined the EF using an ANN. The results demonstrated a satisfactory fuel economy. In [22], an intelligent optimal energy storage system real-time energy management method was introduced by combining an ANN model and a fuzzy-logic controller. A hybrid predictive EMS, based on deep learning networks, combining convolutional neural network (CNN) and bidirectional short and long duration memory Network (LSTM) was proposed. Deep reinforcement learning (DRL) is a combination of deep learning and reinforcement learning. It refers to the use of the feature representation capabilities of deep neural networks to fit functions such as the state, action, and value of reinforcement learning to improve the performance of reinforcement-learning models [23]. The two most popular DRL algorithms are deep Q-network (DQN) and deep deterministic policy gradient (DDPG). In [24], a DRL-model 
based real-time EMS was built by combining a Q-learning and a deep neural network. The evaluation showed that the fuel economy was effectively improved. To further speed up the learning or convergence process, a DDQN with a duelling network structure was also implemented. In [25], an online EMS for hybrid electric tracked vehicle (HETV) was developed based on deep deterministic policy gradient (DDPG) with time-varying weighting factor to further improve economic performance of HETV and reduce computational burden. Additionally, a simulation was conducted to verify the effectiveness and adaptability of the proposed method. Moreover, DDPG was introduced as a SOC reference generator into an MPC framework for energy management for the first time [26].

In recent years, an escalation in research initiatives has been observed to promote intelligent EMSs conscious of current/future driving conditions [27-29]. Most existing methods that are used to provide driving conditions can be classified into the following three categories: (1) global position system (GPS) or intelligent transportation system (ITS)-based driving condition prediction (DCP) methods [4,30], (2) prediction model based DCP methods [5,31], and (3) cluster analysis of historical driving data-based DCR methods. At present, the use of DCP based on GPS and ITS is limited due to the lack of ITS infrastructure and low-level intelligence. The prediction accuracy of the second method relies on the selection and definition of the prediction model. The last category of methods, DCR methods, adopts feature extractions and classification techniques to recognize the driving condition, assuming that the condition remains unchanged in the proceeding few seconds [32]. Under the condition of the development of ITS, the use of DCR-based EMSs is of great significance for the energy distribution of the repetitive driving cycle and become a hot spot for researchers around the world.

There is a need for a comprehensive review of the DCR-based EMSs to better elucidate the state-of-the-art approaches and potential future research directions. To this end, different from the aforementioned review papers in EMSs, the implementation process, DCR algorithms, applications of DCR-based EMSs are generally reviewed in this paper for the first time. The principle of each DCR algorithm along with its pros and cons are illustrated and compared. A comprehensive collection and a survey on the recent DCR-based EMS literature are provided to explore research trends with the overarching goal.

The remainder of the paper is arranged as follows. The implementation of EMSs based on DCR is introduced in Section 2. Several algorithms for DCR are described in Section 3. Applications of DCR in energy management are overviewed in Section 4. Issues and challenges of DCR-based EMSs for PHEVs are elaborated on and analysed in Section 5. Finally, the conclusions are provided in Section 6.

\section{The Implementation Process of DCR-Based EMSs}

In this section, the process to conduct DCR-based EMSs is explained, as is exhibited in Figure 2, in order to introduce the working principle of the method.

(1) Driving-data gathering. Methods for driving-data gathering are classified into the following three categories: the average traffic flow statistics method, the vehicle tracking method, and the autonomous driving method [33]. Considering factors such as experimental costs and traffic conditions, researchers usually adopt the autonomous driving method, which allows drivers to drive according to their personal purposes to build road-condition models [34,35].

(2) Data pre-processing. The collected data is processed to eliminate abnormal values. This mainly includes the following types [36]:

- The loss of GPS signal due to adverse geographical locations such as high-rise buildings and tunnels, which results in discontinuous collection data;

- Abnormal points of acceleration and deceleration (the $100 \mathrm{~km}$ acceleration time of conventional cars is not less than $7 \mathrm{~s}$, and the maximum deceleration speed of emergency braking is $7.5-8.0 \mathrm{~m} \cdot \mathrm{s}^{2}$ );

- Abnormal data collected during a long-term shutdown; 
- Intermittent low-travel speed in the long traffic jam (the maximum speed is less than $10.0 \mathrm{~km} / \mathrm{h}$ ) usually can be treated as idle speed. Generally, idling time exceeding $180 \mathrm{~s}$ is considered abnormal, and the maximum idling time is $180 \mathrm{~s}$.

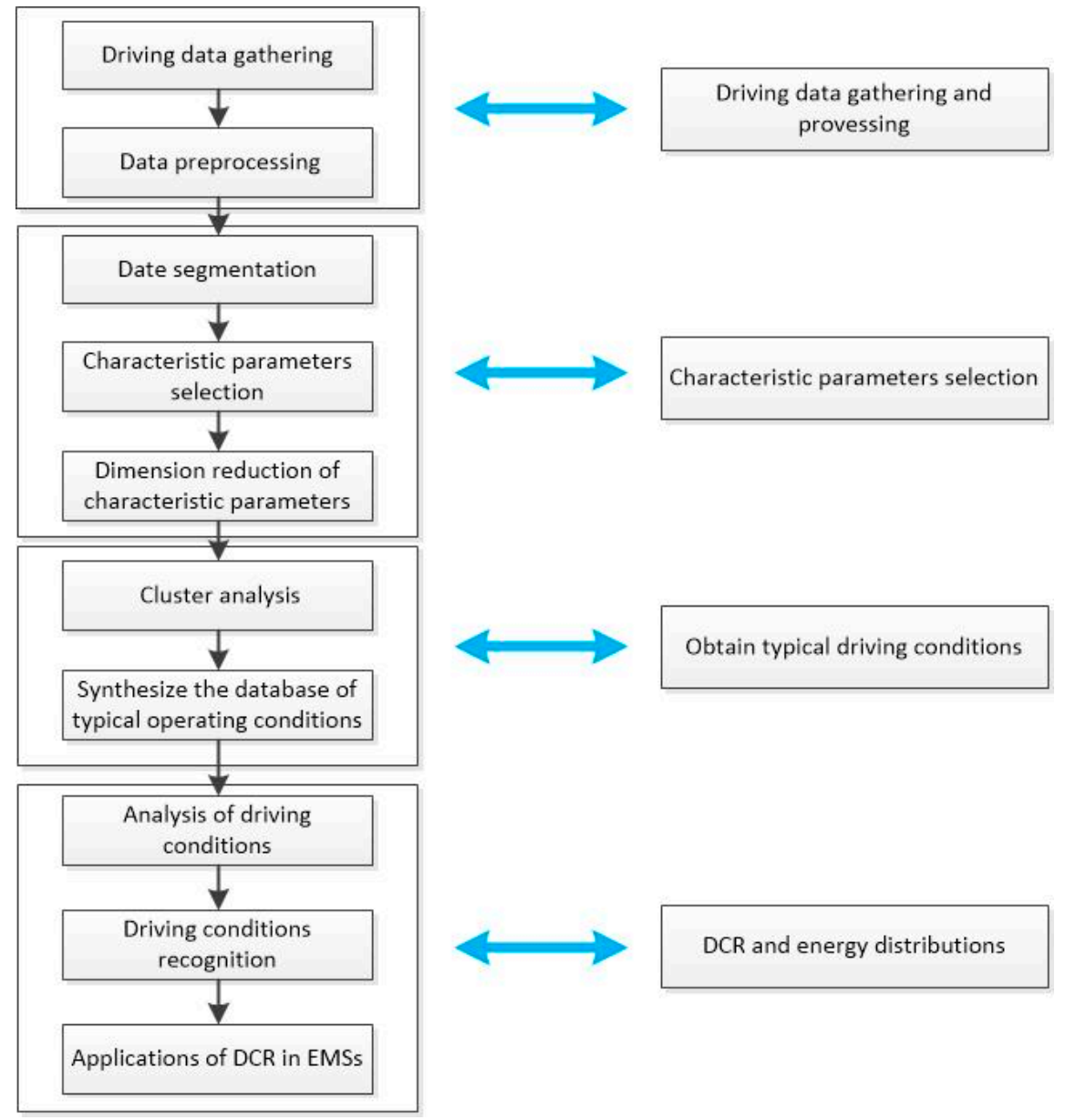

Figure 2. DCR-based EMSs basic problem structure.

To decrease the errors and increase the availability of the data, the following measures are usually taken:

- $\quad$ The interpolation method is used to make up for loss signal;

- Abnormal points of acceleration and deceleration are usually detected by the maximum acceleration value in normal circumstances and the deceleration value of emergency braking, respectively;

- Idle speed data and data during a long-term shutdown should be deleted.

The filter method is usually used to remove white-noise data. Common Filter methods include moving average filtering, wavelet decomposition and reconstruction [37], Fourier filtering [38] and so on.

(3) Date segmentation. The collected speed-time series is split into either kinematic segments or driving segments between two idle speeds. This segmentation is performed for the data characteristics analysis. A complete kinematic segment is usually composed of four driving conditions: idling, accelerating, decelerating, and uniform condition.

(4) Characteristic-parameters selection. Driving features extracted from selected kinematics segments are used as the comparative basis for DCR. There are several parameters representing mode features, such as average speed, maximum speed, and mean acceleration of vehicles. If there are too many parameters, the computational burden is too heavy for real-time control. From another perspective, too few parameters may not demonstrate the difference between driving segments. Various characteristic parameters have different 
effects on vehicle fuel consumption and exhaust emissions. Consequently, it is necessary to select parameters closely related to driving segments.

Zhan [39] took into account the correlation coefficients among parameters, correlation coefficients between parameters and automobile fuel-consumption. Finally, three optimized characteristic parameters were selected. Besides characteristic parameters, Zhang et al. [40] also imported distribution parameters which could verify the similarity of the distribution characteristics of the constructed driving cycles. To construct driving condition with curve information, Sun et al. [41] selected parameters which could represent curve information such as maximum radius, minimum radius and radius variance.

There are also many other methods to select characteristic parameters, such as a boxplot and principal component analysis. Despite the various methods by which to choose characteristic parameters, the first rule is to clarify our research purpose.

(5) Dimension reduction of characteristic parameters. Due to the large matrix of characteristic parameters, a further extraction of characteristic parameters is needed. Commonly used feature-extraction methods include fast Fourier transform (FFT), discrete cosine transform (DCT) and principal component analysis (PCA) [42]. Among them, PCA is a mainstream technique used to reduce the dimension of variables and is usually used for multivariate statistical analysis [43].

According to the steps of principal component analysis, the study in [44] analysed the eigenvalue matrix and obtained six principal components. By comparing eigenvalues of correlation coefficient matrixes and contribution rates, three principal components were used for obtaining initial characteristic parameters, the contribution rate of which reaches $85 \%$ and eigenvalues for which are greater than 1 .

(6) Cluster analysis. It is a statistical classification technique for discovering whether the individuals of a population fall into different groups by performing quantitative comparisons of multiple characteristics. It mainly includes the hierarchical clustering method, two-step clustering method, and K-means clustering method [45]. This kind of problem is typically unsupervised, with features but no labels. Thus, it is impossible to apply supervised learning algorithms. The K-means algorithm, as one of the most classical unsupervised learning algorithms, has been widely used for a long time, due to its advantages of simplicity and efficiency [36]. The K-means clustering method judges categories by distances.

Chen et al. [46,47] applied the K-means clustering algorithm to driving segments classification and verified its effectiveness. Since the random selection of initial clustering centers of the K-means clustering algorithm cannot avoid the disadvantage that the clustering falls into local optima, researchers have optimized and improved it. For example, Gao et al. [48] selected simulated annealing and sequential quadratic programming in the Schittkowski-combining algorithm to optimize initial clustering centers. Zhong et al. [49] optimized the K-means clustering algorithm using the improved PSO algorithm, avoiding local optima and improving accuracy.

(7) Synthesize the database of typical operating conditions. In each category, a fixed number of kinematics segments with the shortest Euclidian distance are selected to synthesize typical operating conditions.

(8) Analysis of driving conditions. Two methods often used in the analysis of driving conditions [50] are the micro-trip method and the driving-segment method. A micro-trip is defined as a velocity profile from stop to stop, as presented in Figure 3. A driving segment is defined as the velocity values in a period with a distinct length, as illustrated in Figure 4. Driving features were extracted from segments found using the above two methods. Owing to the short response time, the driving segment method is most often chosen to analyse working conditions. The time interval for characteristic-parameters calculation was $120 \mathrm{~s}$ before the current time, and the data sampling time was set to $5 \mathrm{~s}$ by Song et al. [51]. Lin et al. $[42,52,53]$ determined that these measures can be accurately extracted using data over a historical window during the preceding $150 \mathrm{~s}$. Nevertheless, there is little research focused on directly recognizing the occurring micro-trip (a speed time series between two 
starts) because its known speed-time series is too short to be correctly recognized at the beginning stage of an occurring micro-trip. Xie et al. [54] addressed this issue by proposing a hybrid method for micro-trip recognition. A hybrid recognition procedure combining the Markov chain prediction model and fuzzy classification model was designed. A statistic approach was presented to estimate the best time to switch between the above two models. The valuation results on real-world driving data suggested that the proposed solution has better accuracy compared to the state-of-the-art approach.

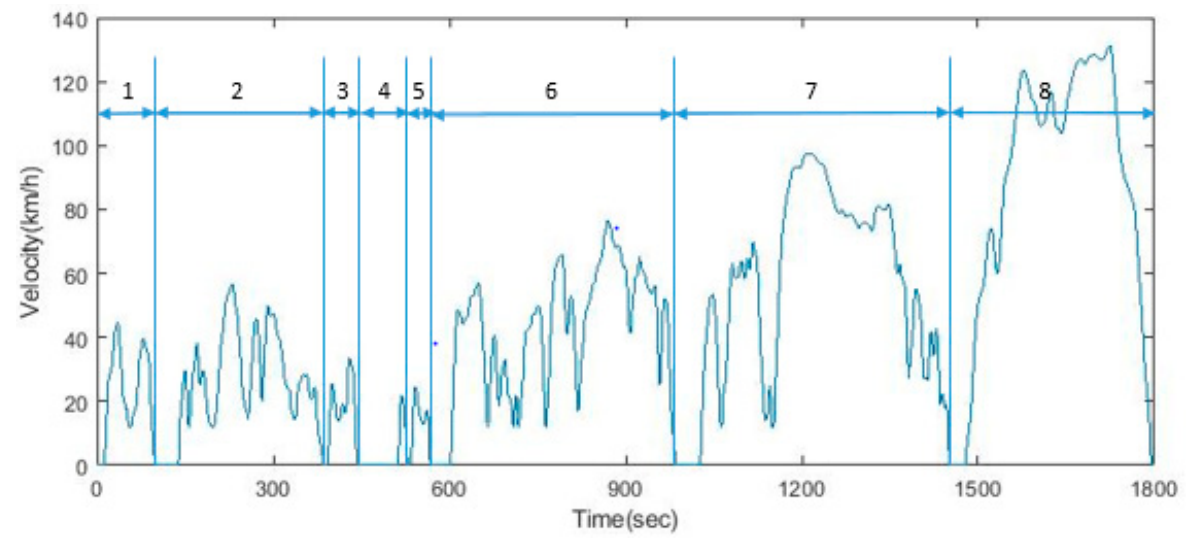

Figure 3. Schematic diagram of micro-trips.

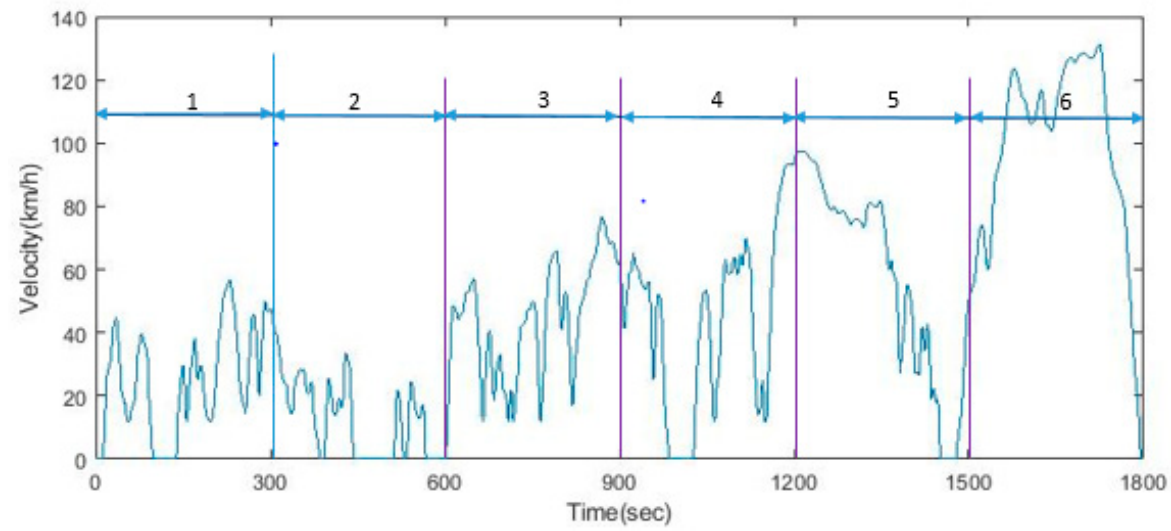

Figure 4. Schematic diagram of driving segments.

(9) Driving conditions recognition. Characteristic parameters such as average speed, maximum acceleration, and the proportion of acceleration time to total time, are employed by DCR algorithms to recognize the current driving condition. The most important factor affecting the accuracy of condition identification is the DCR algorithm chosen.

(10) Applications of DCR in EMSs. Generally, results of condition recognition in energy distributions are used in the application of DCR to energy management.

\section{Several Algorithms for Driving Condition Recognition}

DCR algorithms recognize current driving conditions according to characteristic parameters such as average speed, maximum acceleration and the proportion of acceleration time to total time. The most important factor affecting the accuracy of condition identification is the DCR algorithm chosen. At present, widely used algorithms of DCR mainly include the learning vector quantization (LVQ) neural network, back propagation (BP) neural network, probabilistic neural network (PNN), cluster analysis, support vector machine (SVM), and fuzzy reasoning. This section introduces applications of these algorithms. 


\subsection{DCR Based on LVQ Neural Network}

The LVQ neural network, a kind of forward neural network [55], was proposed by Kohonen [56], with positive effects on classifications and identifications of complex and nonlinear objects. Over the years, several modifications and potential improvements of Kohonen's original LVQ1 procedure have been suggested. Among them, there are three representative algorithms, namely, unsupervised vector quantization (VQ) [57], LVQ+ [58], LVQ2.1 [59]. The winner functions differently in these updates, as they aim at achieving a better approximation of the Bayes optimal decision boundaries, faster or more robust convergence, and stability. Their performance in a typical scenario in terms of their dynamics, sensitivity to initial conditions, and generalizability were analysed [60].

In LVQ, the regularity characteristics of research objects for classification are learnt automatically. The classification of data is based on a comparison with a number of prototype vectors. The similarity is frequently measured in terms of Euclidean distance in feature space. Prototypes are determined in a training phase from the labeled examples and can be interpreted in a straightforward way as they directly represent typical data in the same space [58]. Figure 5 shows the architecture of the LVQ algorithm [61].

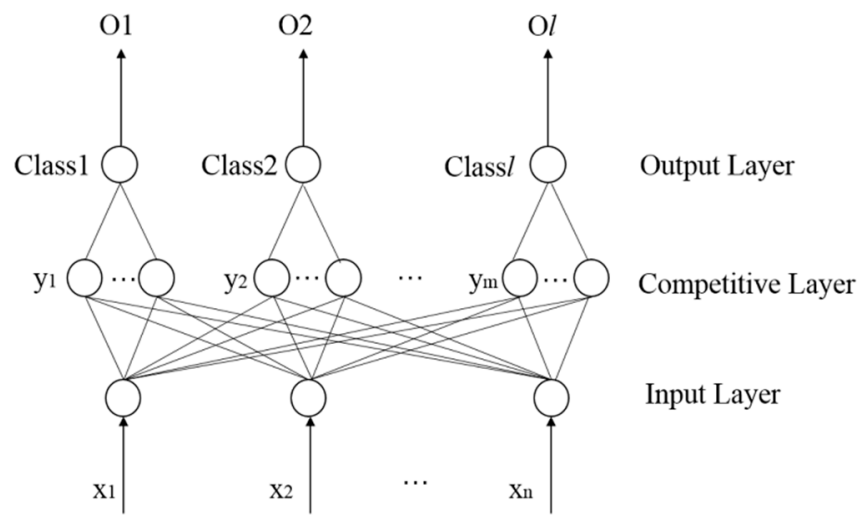

Figure 5. LVQ neural network structure.

He et al., Wang et al., Jiang et al. and Song et al. employed an LVQ neural network to DCR. Their simulation results have validated the effect of this method. He et al. [62] learned, by reading papers, that realizing driving-pattern recognition through calculating the Euclidean distance was more adaptable. Moreover, the LVQ neural network recognition algorithms were based on the calculation of Euclidean distances. By calculating the Euclidean distances of input vectors and the competition layer neurons, neurons in the competition layer can classify the input vectors into subclasses rapidly. So, He et al. employed an LVQ neural network to DCR and the simulation result shows that the pattern identification results of different types of driving cycles were relatively more accurate and stable. He also found that the recognition effect could not be improved obviously when the neuron number was above five and the training time would become much longer. This finding helped to determine the neuron number. Afterward, Wang et al. [63] provided LVQ neural network to DCR, together with micro-trip extraction, box-and-whisker plots and sliding time window. These improved the diversity and magnitude of training samples, while reducing the data convergence time. Jiang et al. [47] found that the error could not be decreased and remained at 0 when the training times were above $62 \mathrm{~s}$. This finding help determine the training times. Overall, in the study by Song et al. [51], an output holding module was added to avoid the frequent variations of the output in a certain period of time, where the module holding time was set to $5 \mathrm{~s}$. This method also contributes to DCR.

\subsection{DCR Based on BP Neural Network}

The BP neural network is a multi-layer feed-forward network trained by an error-back propagation algorithm [64]. Signals and errors are transmitted forward and backwards, 
respectively. After repeated training and modification, the expected convergence value is finally obtained [65]. It can store and learn several in/outputs mappings without describing them mathematically. Its learning rule is to adopt the steepest descent method in which the back propagation is used to regulate the weight value and threshold value of the network to achieve the minimum error sum of square. The topology of the BP neural network model includes the input layer, hidden layer, and output layer, as shown in Figure 6 [66].

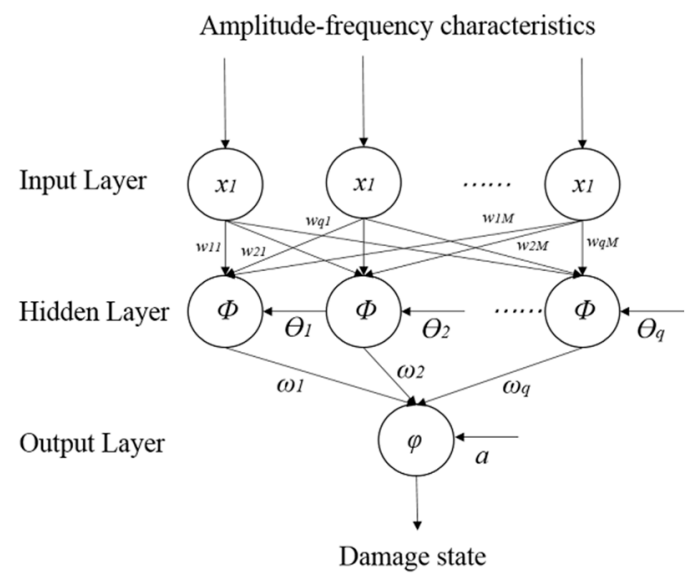

Figure 6. BP neural network structure.

Due to its adoption of the gradient method, the BP neural network experiences problems such as slowly learning convergent velocity and easily converging to the local minimum. The researcher has put forward many improved algorithms to solve these defects. Among these methods, the more typical ones are the additional momentum method, the variable learning-rate method, and the optimization of initial weight [64]. To overcome the shortcomings of a slow convergence rate, an adaptive back propagation algorithm which could update the learning rate and inertia factor automatically based on dynamical training error rate of change was introduced [67].

In the study by Zhang et al. [68], $50 \mathrm{~s}$ was nominated as the training times of the BP neural network, and similarly relevant characteristic parameters such as the current driving velocity, average vehicle velocity, average acceleration, average deceleration, maximum vehicle velocity, maximum acceleration, maximum deceleration, travel distance, and the travel time were regarded as the input nodes of BP network. The influences of different characteristic parameters can be adjusted by adjusting the connection weighting coefficients. The accuracy of test data of the simulation can meet the demand of experiment. In another case investigated by Zhang et al. [69], 100 was nominated as the maximum number of iterations. Seventy percent of sample data were utilized for learning and training, fifteen percent for validation, and the remaining fifteen percent for testing. After 88 iterations, the error was reduced to less than 0.0018 , and the results demonstrated the accuracy of the used neural network. The relationship between the sampling period and recognition accuracy was studied and the author discovered that the maximum recognition accuracy reached $99.99 \%$ when the sampling period was 275 s. The most successful achievements of the BP neural network were made while the accuracy of the network decreased due to problems such as the slow convergence rate and the possibility of falling into local minimum caused by the randomness of its initialization. Moreover, Jiang [70] took advantage of the PSO algorithm (simple principle, few required parameters, fast convergence speed and easy implementation) to optimize the initialization process of the BP network. The simulation results demonstrated that the accuracy was improved to $92 \%$ by the optimized BP network.

From the abovementioned studies, it can be seen that there are many factors, such astraining times, the connection-weighting coefficients, sampling period, prediction period and the initialization process, that are able to influence the accuracy of the BP neural network. Before applying the BP neural network to DCR, it is necessary to set the parameter values above properly. 


\subsection{DCR Based on PNN}

PNNs are evolved from radial basis networks, belonging to feed-forward networks. Its advantages include a simple learning process, fast training speed, accurate classification, fault tolerance and so on. In a PNN, there is no need for massive back-propagation training computations. Instead, each data pattern is represented with a unit that measures the similarity of the input patterns to the data pattern. It is composed of input layer, pattern layer, summation and decision layer, as shown in Figure 7 [71].

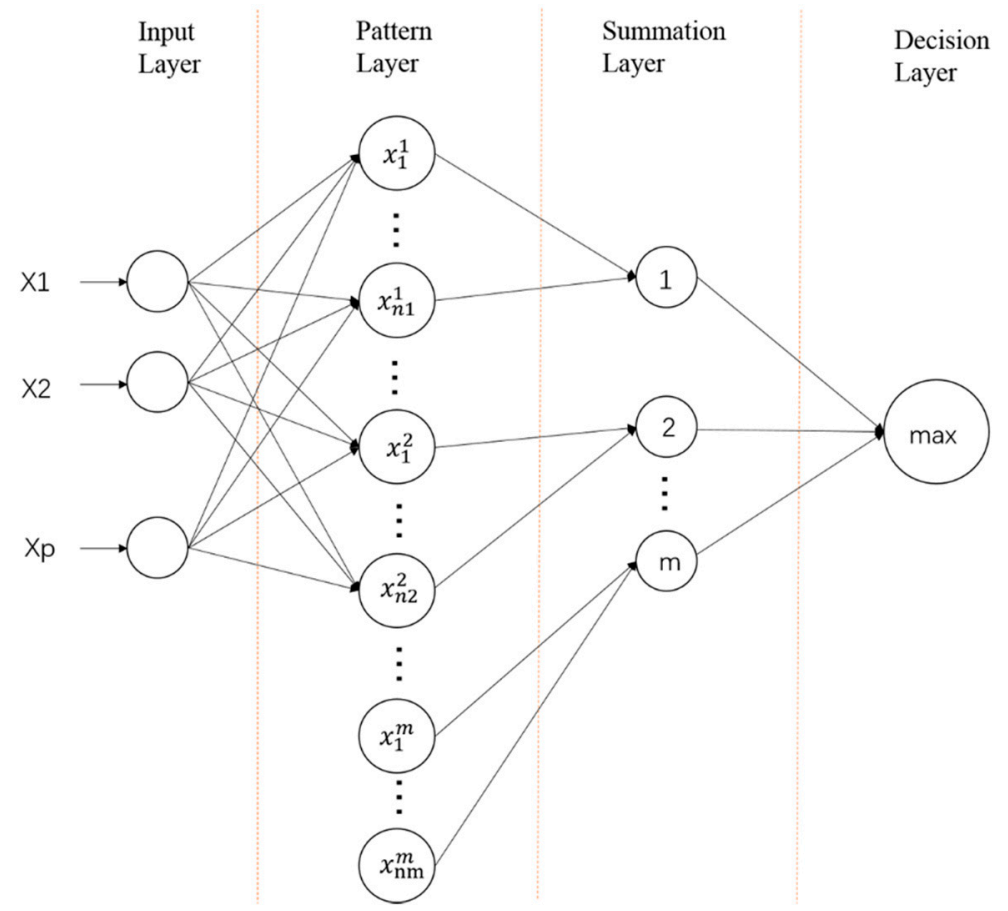

Figure 7. PNN structure.

However, its advantage of a fast training speed comes at the cost of requiring a large memory capacity for operation. Researchers explored ways to overcome this shortcoming. In [72,73], PCA was used to reduce the dimension of the input vectors. Moreover, in order to eliminate the defect of experience value, the key parameter of PNN was optimized by the improved single-target optimization genetic algorithm [74]. A PSO algorithm was proposed to optimize the smoothing factor in PNN [75].

$\mathrm{Hu}$ [76] and Bai [77] et al. adopted PNN in DCR. In Bai's paper, the compound bisected method was used to divide working conditions with a $120 \mathrm{~s}$ cycle, and five characteristic parameters were selected. The identification results indicated that PNN had the ability to identify the category of test-driving conditions accurately. Compared with methods for DCR introduced above, PNN is less frequently used in DCR.

\subsection{DCR Based on Fuzzy Reasoning}

The fuzzy reasoning method is implemented with rules that evolved from controllers' experience but without mathematical models. This strategy is of benefit due to its simplicity and ease of implementation, with execution issues as follows: (1) the setting of membership functions, (2) the definition of fuzzy inference rules. Due to various characteristics of identified driving conditions, different membership functions and fuzzy rules are selected for different simulations.

To increase its ability to manage unclearness, improved fuzzy reasoning with fuzzy knowledge-based systems was carried out [78]. The membership degree was represented by an interval as an alternative of a fuzzy set to remove the drawback of the algorithm [79]. A 
new fuzzy reasoning method was proposed that employed an explicit feedback mechanism to improve the robustness of fuzzy reasoning [80].

The fuzzy reasoning method was used by Yang [81]. In the literature, the language set and membership function of maximum speed, average speed, maximum acceleration and maximum deceleration were established with MATLAB/Simulink fuzzy rule control box. Next, fuzzy inference rules were made for the simulation based on accumulated experience. Finally, the fuzzy identification results were fuzzed properly to obtain the membership functions of the output parameters. Three identified results could be acquired, namely, the congestion driving condition of the city, the smooth driving condition of the city, and the suburban/high-speed condition. The emulation verified the effectiveness of the designed fuzzy recognizer. Likewise, Zhou [82] set four input variables and one output variable for the fuzzy DCR. The input variables and the output variables were four characteristic parameters and the recognition results, respectively. Additionally, the effectiveness of the fuzzy recognizer was also verified.

Furthermore, the fuzzy reasoning method was also applied to drivers' driving style recognition $[83,84]$ and the vehicular-collision tendency estimate [85].

\subsection{DCR Based on Cluster Analysis}

Given the shortcomings of neural networks and fuzzy recognition algorithms, a DCR method based on a cluster analysis is proposed. Driving conditions could be recognized by calculating characteristic parameters of driving conditions to be identified as well as the distance between conditions and clustering centers of all driving conditions. Driving conditions belong to the category nearest to them.

In addition to the partition-based cluster analysis above, the hierarchies-based cluster analysis was proposed by Karypis et al. [86], which does not require the predefined number of groups. To find groups of arbitrary shape and eliminate noise effectively, the densitybased cluster analysis was introduced [87]. To improve computational efficiency, the grid-based cluster analysis was discussed by Wang et al. [88].

The K-means algorithm is most commonly used in the area of driving conditions clustering. Lv et al. $[89,90]$ verified the accuracy of the method. They selected three parameters of average vehicle speed, average absolute acceleration, and idle speed time ratio as characteristic parameters. The accuracy of the method was determined by comparing the results of random conditions to be identified with themselves. However, the K-means algorithm were flawed, without clear distribution boundaries and handling samples with small differences. In view of this situation, Xie et al. [91] applied density based spatial clustering of applications with the noise (DBSCAN) algorithm as the cluster algorithm that can reduce the influence of isolated points on the accuracy of cluster-center coordinates estimation. The clustering performance, according to the DBSCAN clustering result, was better than the result based on the K-means algorithm.

\subsection{DCR Based on SVM}

SVM is a classifier developed from a generalized portrait algorithm in pattern recognitions. Compared with neural networks and other methods, SVM has its unique advantages in pattern recognition due to outstanding learning performance and good capabilities in generalization. Therefore, the method has extensive application prospects in the fields of time prediction, classification, density estimation and so on [92]. An optimized hyperplane for classification has been developed to maximize the area between it and the adjacent samples [93]. Figure 8 provides the sample graph of SVM. 


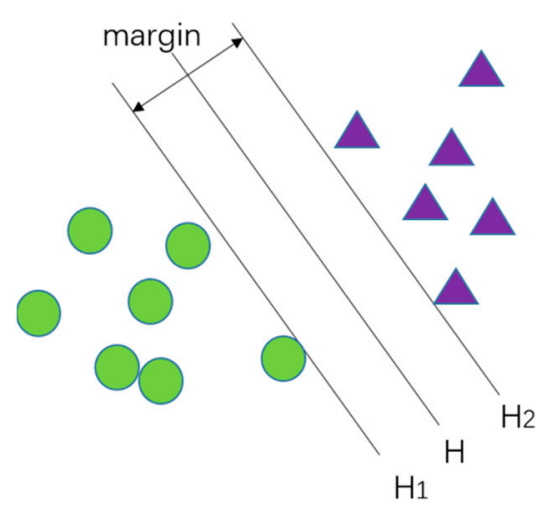

Figure 8. Schematic diagram of optimal classification line.

SVM has been developed for two classes of linearly separable sample data. However, there are still nonlinear and indivisible data that are in a nonideal state in practical application. Therefore, a kernel function was designed and applied to SVM. Considering the differences in generalization and learning ability of different kernel functions, the mixed kernel function was proposed [94].

$\mathrm{Bu}$ [92] applied SVM to DCR. In contrast to the control strategy without drivingcondition recognition, it provided considerable improvement in fuel economy. To improve the application efficiency, Zhang et al. [95] proposed an extended SVM with an embedded feature-selection ability, allowing the driving-condition discrimination system to achieve higher recognition efficiency and robustness. However, the current forecast methods predict the speed mostly based on traffic conditions while ignoring the impact of the driver-vehicleroad system on the actual speed profile. To compensate for the above deficiencies, a model was constructed by Li et al. to effectively incorporate the factors of the driver-vehicle-road traffic system for a faithful speed representation, such as driving habits (driver), vehicle state (vehicle), geographic information (road) and traffic flow (traffic) [96]. The optimized genetic algorithm-SVM (GA-SVM) vehicle-speed prediction model was established in accordance with the optimized GA-SVM prediction algorithm at different times. Moreover, the validity and rationality of the prediction algorithm were confirmed by the test results. To improve the accuracy of classification and recognition, Zhang [97] applied the PSO algorithm to optimize the core parameters of SVM. Compared with the BP neural network, the proposed algorithm achieved a better recognition and classification effect.

\subsection{Other Identification Methods of Working Conditions}

In addition to the methods mentioned above, various methods have been applied to DCR. For instance, Lu [98] established a driving-state recognition model based on the naive Bayesian classifier. Hailong et al. [99] proposed a method of driving state recognition based on the PSO algorithm. Ba [35] used the random forest algorithm to achieve real-time performance, laying a foundation for the implementation of the subsequent coupled energy management strategy established in the paper.

Despite the wider usage, the application of such classification algorithms in DCR is yet to be well compared. Due to different driving conditions, weights of neural networks, number of neurons and layers and confidence-intervals overlap, it would be difficult to make a fair appraisal of DCR algorithms' performance. Nonetheless, all the foregoing DCR approaches are summarized in Table 1 according to their principles, with their main characteristics. 
Table 1. Main DCR methods characteristics summary.

\begin{tabular}{cll}
\hline Methods & \multicolumn{1}{c}{ Main Advantages } & \multicolumn{1}{c}{ Main Disadvantages } \\
\hline LVQNN & $\begin{array}{l}\text { High learning, adaptive and fault-tolerant ability } \\
\text { Fast computation }\end{array}$ & $\begin{array}{l}\text { Space waste and iteration time increase } \\
\text { (Some neurons cannot be enabled) } \\
\text { Accuracy: initial weights selected by experience }\end{array}$ \\
\hline BPNN & High learning and fault-tolerant ability & $\begin{array}{l}\text { Local minimization } \\
\text { Slow convergence speed }\end{array}$ \\
PNN & $\begin{array}{l}\text { Simple learning process } \\
\text { Less training computation time } \\
\text { High accuracy and fault-tolerant ability } \\
\text { Escape from local optima }\end{array}$ & $\begin{array}{l}\text { Accuracy: the spread value selected by experience } \\
\text { The requirement of massive memory for operation }\end{array}$ \\
\hline Fuzzy & $\begin{array}{l}\text { Simple learning process and strong robustness } \\
\text { Reasoning }\end{array}$ & $\begin{array}{l}\text { Accuracy: the selection of membership degree } \\
\text { mostly depends on experience }\end{array}$ \\
\hline Analysis & $\begin{array}{l}\text { Free from the constraint and interference of } \\
\text { prior knowledge } \\
\text { Clear division rules and fast convergence speed }\end{array}$ & $\begin{array}{l}\text { Sensitive to abnormal data } \\
\text { K value to be determined }\end{array}$ \\
\hline SVM & $\begin{array}{l}\text { Strong learning and generalization ability } \\
\text { Wide comprehension } \\
\text { Strong universality and robustness }\end{array}$ & $\begin{array}{l}\text { Difficult implementation for large training pattern } \\
\text { set and multi-classification problems }\end{array}$ \\
\hline
\end{tabular}

\section{The Application of DCR in EMSs of PHEVs}

Research has revealed the significance of DCR for PHEVs [68,69,92]. The basic idea of EMSs based on DCR is to apply the results of DCR to problems of energy distribution. The applications of DCR in RB-based EMSs and optimal-based EMSs are discussed in the following section. This section provides a comprehensive survey of applications of DCR in PHEV EMSs, including RB-based EMSs and optimal-based EMSs. Figure 9 illustrates a schematic of the DCR-based EMS.

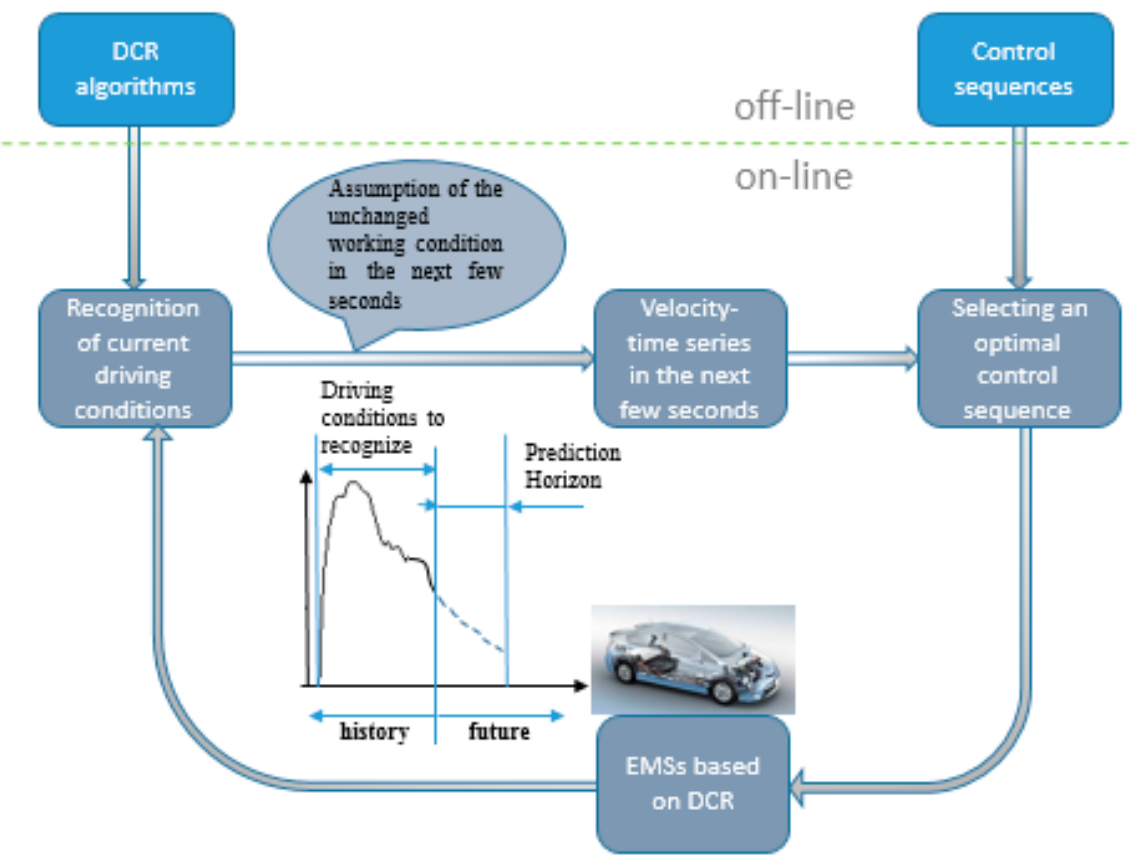

Figure 9. A schematic of the EMS based on DCR.

The invariable EMS based on the determined rules cannot completely take advantage of the known information of driving conditions. Therefore, researchers pay attention to the optimization of control parameters in determined RB-based EMSs using DCR. With 
the known driving conditions, Lv et al. [89] adopted PSO algorithm to optimize control parameters in the logical threshold control strategy, and provided a decrease of $5.45 \%$ for fuel consumption.

In contrast to rule-based EMSs, the control strategy based on fuzzy rules is more widely utilized in energy distribution with DCR due to its advantages of self-learning, adaptability and robustness. Neural networks, though widely used in pattern recognition and classification with outstanding training and learning performance, are not suitable for rule-based knowledge representation. Nevertheless, knowledge extraction and rule representation, which are more convenient in fuzzy systems, are suitable for fuzzy or qualitative knowledge, but lack the adaptability of self-learning and adaptation. The complementary advantages of DCR based on neural networks and EMSs based on fuzzy rules make the implementation of fuzzy reasoning based on DCR easy. In their study, DCR was realized with neural networks by Zhang et al. [68]. The recognition results were considered as reference inputs of the fuzzy controller. Fuzzy control rules and membership functions can be adjusted and optimized according to driving information, so as to avoid the poor pertinence of driving cycles. Besides, the combination of fuzzy rulebased control strategy and DCR methods based on SVM and fuzzy reasoning also achieved good results. Compared to the fuzzy EMS, the fuel consumption of the optimized EMS under the NEDC cycle was reduced from $7.093 \mathrm{~L} / 100 \mathrm{~km}$ to $5.576 \mathrm{~L} / 100 \mathrm{~km}$, and the fuel optimization rate reached $21.39 \%$; CO emissions decreased from $5.362 \mathrm{~g} / \mathrm{km}$ to $4.419 \mathrm{~g} / \mathrm{km}$, a $17.59 \%$ reduction; NOx emissions decreased from $1.910 \mathrm{~g} / \mathrm{km}$ to $1.524 \mathrm{~g} / \mathrm{km}$, a $20.21 \%$ reduction; HC emissions decreased from $0.5702 \mathrm{~g} / \mathrm{km}$ to $0.4054 \mathrm{~g} / \mathrm{km}$, a $28.90 \%$ reduction. Zhang [97] established a DCR model based on SVM, adopted a fuzzy control strategy for torque distribution between two powers, and optimized certain subjective parameters of fuzzy control with a tabu search and immune particle-swarm algorithm. Compared to CS-CD EMS, the proposed EMS achieved a decrease of $9.9 \%$ of fuel consumption, $8.3 \%$ of $\mathrm{HC}$ emission, $9.3 \%$ of $\mathrm{CO}$ emission and $9.5 \%$ of $\mathrm{NO}_{\mathrm{x}}$ emission. The fuzzy torque distributor, based on the reference trajectory of theoretical SOC designed by Zhou [82], provided a considerable improvement in the control effect, assuming the validity of the pre-set range. Therefore, a reasonable EMS should take the vehicle's range of the day into account. Additionally, Lu [98] achieved the online application of the current driving route through recognition by the naive bayes algorithm, divided driving conditions into fixed driving conditions and uncertain driving conditions, and adopted different control strategies. For fixed driving conditions, the fuzzy control strategy was developed to distribute the torque between the engine and the motor following the theoretical SOC curve. For frequently used routes under uncertain conditions, the algorithm of neural networks was used for driving-condition prediction, the corresponding fuzzy control algorithm that adjusts control parameters was developed for different prediction results, and the overall energy distribution was adjusted according to basic principles of electricity usage. Then, the simulation results demonstrated the effectiveness of the proposed algorithm.

Since DCR provides more accurate ranges for the optimization of control strategies, the optimization-based control strategy was applied to the control strategy based on DCR. The control strategy based on ECMS is representative of real-time optimization-based EMSs. DCR-based ECMS emphasizes the adjusting and optimizing of equivalent factors of ECMS according to identified conditions. To improve fuel economy, Liu [90] adaptively adjusted the equivalent factor under driving conditions which was recognized by the K-means clustering algorithm and the real-time SOC value of the battery. The method led to a decrease in fuel consumption by $6.9 \%$ and an engine efficiency increase of $2 \%$. Likewise, PSO was applied by Zhang et al. [69] to optimize the key parameters of ECMS with the assigned driving cycles. Furthermore, $\mathrm{Bu}$ [92] developed two EMSs based on battery energy observation and fuzzy rules. In the EMS based on battery energy observation, ECMS was applied to energy management by the battery energy observation unit.

The global optimal control strategy can achieve the global optimal solution while the online application is limited because global driving conditions cannot be achieved. 
With the popularity of DCR algorithms, combinations of DCR and global optimization strategies are widely utilized. For example, Chen [46] optimized the database of typical driving conditions globally and established the database of optimal control sequence to realize the real-time application. The overall and instantaneous driving-condition weight factors were defined to calculate the real-time scale factor and the torque distribution ratio of the hybrid power system, along with the database of the optimal control sequence. The EMS designed achieved a $8.5 \%$ decrease in fuel consumption compared to the rulebased EMS. Ba [35] developed the Coupled EMS (ECMS-SDP), in which a random forest algorithm was utilized to recognize driving conditions and in which online control laws of SDP based on 'mathematical expected optimal' were calculated offline. Considering that drivers could obtain the range in advance through relevant map software and intelligent transportation systems, the improved adaptive coupled EMS was developed to further improve the economic performance by $14.8 \%$ compared with ECMS-SDP. This method is suited to the development direction of intelligent transportation systems in the future.

Besides, more EMSs have been combined with DCR. A novel control adaptive realtime EMS for commuter PHEVs was proposed by Li P et al. [100]. Its main feature was that the fuzzy inference system for online estimation of the reference SOC and adaptive update law with traffic recognition were blended into the mainframe of an adaptive-ECMS. The simulation comparisons confirmed that the designed EMS achieve further improvement of the fuel economy, with a reduction of $22.98 \%$ and $10.26 \%$ compared with the RB strategy and the ECMS in the same driving environment, respectively.

In this section, DCR-based EMSs are described, the collocation cases of different control strategies and DCR are enumerated, and the effects of different cases are analysed.

\section{Issues and Challenges}

Based on the literature review in the previous sections, DCR-based EMSs have been researched extensively. At the same time, there are a wide selection of methods at every stage of EMSs implementation. How to make the right choice at every stage is a key challenge. The issues and challenges during the implementation of the DCR-based EMSs are discussed in this section.

\subsection{The Recognition Windows Settings}

The window settings of DCR, with the most important element being the identificationwindow size, greatly improve recognition accuracy. At present, the identification objects are mostly sliding windows of a fixed step size [42]. The identification-window size is a parameter that has to be adjusted to attain the maximum of identification success over the reference cycle [101]. Some researchers applied themselves to designing the optimum window size [102], which could reveal the feature of the current driving segment comprehensively without computational burden. However, the method of fixed window size cannot produce accurate results [103] and easily hides the characteristics of the current micro-stroke in statistical data [54], resulting in identification errors. At present, correlational studies for the above problems are not adequate.

\subsection{The Methods for DCR}

Various categories of algorithms were initially applied to DCR $[47,62,63,68,70,76,77,81,82$, $89,90,92]$. Due to their native defect in principles, researchers tried to optimize the methods by combining them with other algorithms [51,70,91,95-97]. Qualified methods are expected to have the characteristics of adaptability [51], speed [70] and accuracy [96]. Despite numerous studies on DCR, the method for optimizing any arbitrary drive cycles has not yet been found. Furthermore, it is unscientific to compare the conclusions of experiments directly due to use of different simulation models in different studies. Thus, the benchmark for simulation of DCR-based EMS is needed. 


\subsection{Utilization of Intelligent Transportation Systems (ITS)}

ITS combines high technology and improvements in information systems, communication, sensors, controllers and advanced mathematical methods with the conventional world of transportation infrastructure [104]. Data-collection components gather all the observable information from the transportation system for a further analysis of the current traffic conditions [105]. Global Positioning System (GPS) data are becoming more widely available for the analysis of traffic conditions or even travel behavior [106]. Utilizing the interaction and synergy of smart grid and ITS, PHEV owners optimize their charging behavior based on the multidimensional data of traffic conditions, charging prices and waiting time at EV charging stations [107]. With these advanced techniques in intelligent-vehicle development, considerable progress can be made towards improving energy efficiency and driving performance.

\subsection{Multi-Objective Optimization}

Fuel economy [90] and emission characteristics [68,97] are mostly considered in the design of EMSs. However, most fuel-efficient conditions are different from that of emissions [108]. This leads to a need for EMSs to solve the multi-objective optimization problem. In real-world applications, many other design concerns should also be considered, such as drivability for comfort and battery health for cost-effectiveness [109]. Multi-objective approaches give overall consideration to objectives [110]. It can neither cover up the influence of one target nor simply perform the equivalent treatment. Instead, it should hierarchically coordinate contradictions among targets according to the importance of targets. Thus, EMSs to solve the multi-objective optimization problem still need to be further explored.

\section{Conclusions}

In this study, the DCR-based EMSs of HHEVs have been extensively studied and compared. There are 10 steps to implement DCR-based energy management. The method works only when appropriate modes of data manipulation are chosen throughout the process. Therefore, it is concluded that the parameters should be set correctly.

Neural networks, cluster analysis, SVM, and fuzzy reasoning are applied to recognize driving conditions. We should not measure their performance based solely on convergence speed or fuel consumption, since characteristic parameters and results are different across different studies, which greatly impacts the simulation results. Even so, Table 1 summarizes the pros and cons of all the mentioned methods of principle analysis in the relevant literature, which can help researchers select the appropriate algorithm to fulfill their research needs.

Theoretically, current literature studies suggest that PHEVs EMSs based on DCR have a significant potential to save fuel and enhance environmental protection. Cited studies have demonstrated that applying historical driving information leads to a decrease in fuel consumption and pollutant emission. The continuous development of technology will certainly promote PHEVs for future transportation and help in driving the PHEV market.

Finally, challenges of DCR-based EMSs of PHEVs are discussed. These challenges bring up four suggestions for future trends to encourage more innovative ideas in this area:

- Explore better methods for recognition-windows settings;

- Explore the optimal method for DCR;

- Develop and apply ITS for efficient PHEV control;

- Study EMSs for the multi-objective optimization problem.

Author Contributions: Conceptualization, C.L. and Y.L.; methodology, C.L.; investigation, C.L.; resources, C.L.; data curation, Y.L.; writing-original draft preparation, C.L. and Y.L.; writingreview and editing, C.L. and Y.L.; visualization, C.L.; supervision, Y.L.; project administration, Y.L. All authors have read and agreed to this version of the manuscript.

Funding: This research received no external funding. 
Conflicts of Interest: The authors declare no conflict of interest.

\section{References}

1. Banvait, H.; Anwar, S.; Chen, Y. A rule-based energy management strategy for plug-in hybrid electric vehicle (PHEV). In Proceedings of the 2009 American Control Conference, St. Louis, MO, USA, 10-12 June 2009; pp. 3938-3943.

2. Shen, Y.; Ge, G.; Liu, A.; Zheng, Z. Operation of an ICE/PM/TTRB APU in a Range Extender Electric Vehicle Power-Train. In Proceedings of the 2019 IEEE Innovative Smart Grid Technologies-Asia (ISGT Asia), Chengdu, China, 21-24 May 2019; pp. 3205-3210.

3. Li, Q.; Chen, W.; Li, Y.; Liu, S.; Huang, J. Energy management strategy for fuel cell/battery/ultracapacitor hybrid vehicle based on fuzzy logic. Int. J. Electr. Power Energy Syst. 2012, 43, 514-525. [CrossRef]

4. Jun, L.; Faming, Z.; Xiong, T.; Biao, L.; Wenbin, W. Simulation research on PHEV based on fuzzy logic control strategies. J. Chongqing Jiaotong Univ. 2013, 2, 329-334.

5. Sabri, M.F.M.; Danapalasingam, K.A.; Rahmat, M.F.a. Improved fuel economy of through-the-road hybrid electric vehicle with fuzzy logic-based energy management strategy. Int. J. Fuzzy Syst. 2018, 20, 2677-2692. [CrossRef]

6. Denis, N.; Dubois, M.R.; Desrochers, A. Fuzzy-based blended control for the energy management of a parallel plug-in hybrid electric vehicle. IET Intell. Transp. Syst. 2015, 9, 30-37. [CrossRef]

7. Li, P.; Li, Y.; Wang, Y.; Jiao, X. An intelligent logic rule-based energy management strategy for power-split plug-in hybrid electric vehicle. In Proceedings of the 2018 37th Chinese Control Conference (CCC), Wuhan, China, 25-27 July; pp. $7668-7672$.

8. Serrao, L.; Onori, S.; Rizzoni, G. A comparative analysis of energy management strategies for hybrid electric vehicles. J. Dyn. Sys. Meas. Control 2011, 133, 31012. [CrossRef]

9. Liu, J.; Chen, Y.; Li, W.; Shang, F.; Zhan, J. Hybrid-trip-model-based energy management of a PHEV with computation-optimized dynamic programming. IEEE Trans. Veh. Technol. 2017, 67, 338-353. [CrossRef]

10. Chen, Z.; Mi, C.C.; Xu, J.; Gong, X.; You, C. Energy management for a power-split plug-in hybrid electric vehicle based on dynamic programming and neural networks. IEEE Trans. Veh. Technol. 2013, 63, 1567-1580. [CrossRef]

11. Gong, Q.; Li, Y.; Peng, Z.-R. Trip based optimal power management of plug-in hybrid electric vehicles using gas-kinetic traffic flow model. In Proceedings of the 2008 American Control Conference, Seattle, WA, USA, 11-13 June 2008; pp. 3225-3230.

12. Du, W.; Zhao, S.; Jin, L.; Gao, J.; Li, H. Parameter optimization of rule-based control strategy for multi-mode hybrid electric vehicle. Proc. Inst. Mech. Eng. Part D J. Automob. Eng. 2020, 234, 2706-2716. [CrossRef]

13. Zhang, F.; Hu, X.; Xu, K.; Tang, X.; Cui, Y. Research status and prospect of energy management based on model prediction for hybrid electric vehicles. Chin. J. Mech. Eng.-Engl. 2019, 55, 86-108. [CrossRef]

14. Lin, C.-C.; Peng, H.; Grizzle, J. A stochastic control strategy for hybrid electric vehicles. In Proceedings of the 2004 American Control Conference, Boston, MA, USA, 30 June-2 July 2004; pp. 4710-4715.

15. Zhang, Y.; Guo, C.; Li, G.; Liu, Y.; Chen, Z. Cooperative control strategy for plug-in hybrid electric vehicles based on a hierarchical framework with fast calculation. J. Clean. Prod. 2020, 251, 119627. [CrossRef]

16. Zeng, Y.; Cai, Y.; Kou, G.; Gao, W.; Qin, D. Energy management for plug-in hybrid electric vehicle based on adaptive simplifiedECMS. Sustainability 2018, 10, 2060. [CrossRef]

17. Wang, W.; Cai, Z.; Liu, S. Design of Real-Time Control Based on DP and ECMS for PHEVs. Math. Probl. Eng. 2021, $2021,6667614$. [CrossRef]

18. Karbowski, D.; Kim, N.; Rousseau, A. Route-based online energy management of a PHEV and sensitivity to trip prediction. In Proceedings of the 2014 IEEE Vehicle Power and Propulsion Conference (VPPC), Coimbra, Portugal, 27-30 October 2014; pp. 1-6.

19. Han, S.; Zhang, F.; Ren, Y.; Xi, J. Predictive Energy Management Strategies in Hybrid Electric Vehicles Using Hybrid Deep Learning Networks. China J. Highw. Transp. 2020, 33, 1-9.

20. $\mathrm{Hu}, \mathrm{H}$. Research on Energy Management Strategy for Plug-in Hybrid Electric Vehicle Based on Reinforcement Learning; Kunming University of Science and Technology: Kunming, China, 2020.

21. Xie, S.; Hu, X.; Qi, S.; Lang, K. An artificial neural network-enhanced energy management strategy for plug-in hybrid electric vehicles. Energy 2018, 163, 837-848. [CrossRef]

22. Feng, Y.; Dong, Z. Optimal energy management with balanced fuel economy and battery life for large hybrid electric mining truck. J. Power Sources 2020, 454, 227948. [CrossRef]

23. Yang, S.; Shan, Z.; Ding, Y.; Li, G. The Research Status and Prospects of Deep Reinforcement Learning. Comput. Eng. 2021, 41, 1-18. [CrossRef]

24. Qi, X.; Luo, Y.; Wu, G.; Boriboonsomsin, K.; Barth, M. Deep reinforcement learning enabled self-learning control for energy efficient driving. Transp. Res. Part C Emerg. Technol. 2019, 99, 67-81. [CrossRef]

25. Ma, Z.; Huo, Q.; Zhang, T.; Hao, J.; Wang, W. Deep Deterministic Policy Gradient Based Energy Management Strategy for Hybrid Electric Tracked Vehicle With Online Updating Mechanism. IEEE Access 2021, 9, 7280-7292. [CrossRef]

26. Huang, R.; He, H.; Meng, X.; Li, M. A Novel Hierarchical Predictive Energy Management Strategy for Plug-in Hybrid Electric Bus Combined with Deep Reinforcement Learning. In Proceedings of the 2021 International Conference on Electrical, Computer, Communications and Mechatronics Engineering (ICECCME), Mauritius, Mauritius, 7-8 October 2021; pp. 1-5.

27. Vadamalu, R.S.; Beidl, C. Online MPC based PHEV Energy Management using conic interior-point methods. In Proceedings of the 2016 IEEE Intelligent Vehicles Symposium (IV), Gothenburg, Sweden, 19-22 June 2016; pp. 466-471. 
28. Jinquan, G.; Hongwen, H.; Jiankun, P.; Nana, Z. A novel MPC-based adaptive energy management strategy in plug-in hybrid electric vehicles. Energy 2019, 175, 378-392. [CrossRef]

29. He, H.; Wang, Y.; Han, R.; Han, M.; Bai, Y.; Liu, Q. An improved MPC-based energy management strategy for hybrid vehicles using V2V and V2I communications. Energy 2021, 225, 120273. [CrossRef]

30. Sharma, V.; Purwar, S. Nonlinear controllers for a light-weighted all-electric vehicle using Chebyshev neural network. Int. J. Veh. Technol. 2014, 2014, 867209. [CrossRef]

31. Montazeri-Gh, M.; Mahmoodi-K, M. Optimized predictive energy management of plug-in hybrid electric vehicle based on traffic condition. J. Clean. Prod. 2016, 139, 935-948. [CrossRef]

32. Jeon, S.-I.; Jo, S.-T.; Park, Y.-I.; Lee, J.-M. Multi-mode driving control of a parallel hybrid electric vehicle using driving pattern recognition. J. Dyn. Sys. Meas. Control 2002, 124, 141-149. [CrossRef]

33. Li, N. The Construction and Study of Vehicle Driving Cycle Based on Urban Road; Hebei Agricultural University: Baoding, China, 2013

34. Fu, X. Research on Parameter Optimized Matching and Energy Management Strategy for Hybrid Electric Vehicle; Shandong University: Jinan, China, 2015

35. Ba, M. Research on the Control Strategy of Plug-in Hybrid Electric Vehicle Based on Multi-Condition Optimization; Jilin University: Changchun, China, 2018.

36. Guo, J.; Jiang, H.; Lei, S.; Zhong, Z.; Zuo, H.; Xu, J. Vehicle driving cycle construction method of urban roads. J. Traffic Transport. Eng. 2020, 20, 197-209.

37. Zhang, Y.; Su, X.; Gao, G.; Shang, Y. Driving Conditions of a Car Based on Improved Principal Component and K-means Clustering Algorithm. Sci. Technol. Eng. 2021, 21, 3199-3205.

38. CAO, Q.; LI, J.; LIU, Y.; QU, D.-w. Construction of driving cycle based on big data and markov chain. J. Northeast. Univ. 2019, $40,77$.

39. Zhan, S. Energy Management Strategy of Hybrid Electric Vehicle Based on the Recognition of Driving Cycle and Driving Style. Ph.D. Thesis, Chongqing University, Chongqing, China, 2016.

40. Zhang, J.; Wang, Z.; Liu, P.; Zhang, Z.; Li, X.; Qu, C. Driving cycles construction for electric vehicles considering road environment: A case study in Beijing. Appl. Energy 2019, 253, 113514. [CrossRef]

41. Sun, W.; Rong, J.; Wang, J.; Xu, J.; Lv, S.; Liu, L. Research on the Construction Method of Urban Compound Driving Cycle with Curved Road Information. Automot. Eng. 2021, 43, 1519-1527. [CrossRef]

42. Huang, X.; Tan, Y.; He, X. An intelligent multifeature statistical approach for the discrimination of driving conditions of a hybrid electric vehicle. IEEE Trans. Intell. Transp. Syst. 2010, 12, 453-465. [CrossRef]

43. Pinkowski, B. Principal component analysis of speech spectrogram images. Pattern Recognit. 1997, 30, 777-787. [CrossRef]

44. Guo, S.; Wu, K.; Zhang, G. Application of PCA-K-means++ combination model to construction of light vehicle driving conditions in intelligent traffic. J. Meas. Eng. 2020, 8, 107-121. [CrossRef]

45. Qin, S.; Yubo, Z.; Ping, J. A research on driving cycle of city roads based on micro-trips. Automot. Eng. 2011, 33, $256-261$.

46. Chen, Y. Study on Control Strategy of Hybrid Electric Vehicle Based on Working Condition Recognition; Shandong University: Jinan, China, 2017.

47. Jiang, T. Research on Control Strategy for the Plug-in Hybrid Electric Vehicle Based on Driving Cycle Identification; Hefei University of Technology: Hefei, China, 2018.

48. Gao, J.; Zhang, L.; Sun, Z.; Xi, J. The of Control strategy optimization of Plug-in Hybrid Electric Vehicle based on driving cycles. Chin. J. Mech. Eng. 2017, 28, 1770-1777.

49. Zhong, Y. Hybrid Electric Vehicle Considering Different Road Spectrum and Driving Style; Shandong University: Jinan, China, 2019.

50. Fotouhi, A.; Yusof, R.; Rahmani, R.; Mekhilef, S.; Shateri, N. A review on the applications of driving data and traffic information for vehicles' energy conservation. Renew. Sustain. Energy Rev. 2014, 37, 822-833. [CrossRef]

51. Song, K.; Li, F.; Hu, X.; He, L.; Niu, W.; Lu, S.; Zhang, T. Multi-mode energy management strategy for fuel cell electric vehicles based on driving pattern identification using learning vector quantization neural network algorithm. J. Power Source 2018, 389, 230-239. [CrossRef]

52. Lin, C.-C.; Jeon, S.; Peng, H.; Lee, J.M. Driving pattern recognition for control of hybrid electric trucks. Veh. Syst. Dyn. 2004, 42, 41-58. [CrossRef]

53. Montazeri-Gh, M.; Fotouhi, A. Traffic condition recognition using the k-means clustering method. Sci. Iran. 2011, 18, 930-937. [CrossRef]

54. Xie, H.; Tian, G.; Du, G.; Huang, Y.; Chen, H.; Zheng, X.; Luan, T.H. A hybrid method combining Markov prediction and fuzzy classification for driving condition recognition. IEEE Trans. Veh. Technol. 2018, 67, 10411-10424. [CrossRef]

55. Pham, D.; Otri, S.; Ghanbarzadeh, A.; Koc, E. Application of the bees algorithm to the training of learning vector quantisation networks for control chart pattern recognition. In Proceedings of the 2006 2nd International Conference on Information \& Communication Technologies, Damascus, Syria, 24-28 April 2006; pp. 1624-1629.

56. Kohonen, T. Learning Vector Quantization; Springer Press: Berlin/Heidelberg, Germany, 2001

57. Lancini, R.; Perego, F.; Tubaro, S. Neural network approach for adaptive vector quantization. In Proceedings of the ICASSP-92: 1992 IEEE International Conference on Acoustics, Speech, and Signal Processing, San Francisco, CA, USA, 23-26 March 1992; pp. 389-392. 
58. Biehl, M.; Ghosh, A.; Hammer, B. Learning vector quantization: The dynamics of winner-takes-all algorithms. Neurocomputing 2006, 69, 660-670. [CrossRef]

59. Seo, S.; Obermayer, K. Soft learning vector quantization. Neural Comput. 2003, 15, 1589-1604. [CrossRef] [PubMed]

60. Ghosh, A.; Biehl, M.; Hammer, B. Performance analysis of LVQ algorithms: A statistical physics approach. Neural Netw. 2006, 19, 817-829. [CrossRef] [PubMed]

61. Wang, B.; Chen, Q.; Wang, Z.; Hu, Y. The Rearch on Improved LVQ Neural Network Method. In Proceedings of the 2019 3rd International Conference on Circuits, System and Simulation (ICCSS), Nanjing, China, 13-15 June 2019; pp. $206-209$.

62. He, H.; Sun, C.; Zhang, X. A method for identification of driving patterns in hybrid electric vehicles based on a LVQ neural network. Energies 2012, 5, 3363-3380. [CrossRef]

63. Wang, J.; Wang, Q.; Zeng, X.; Wang, P.; Wang, J. Driving cycle recognition neural network algorithm based on the sliding time window for hybrid electric vehicles. Int. J. Automot. Technol. 2015, 16, 685-695. [CrossRef]

64. Li, J.; Cheng, J.-h.; Shi, J.-y.; Huang, F. Brief introduction of back propagation (BP) neural network algorithm and its improvement. In Advances in Computer Science and Information Engineering; Springer: Berlin/Heidelberg, Germany, 2012; pp. 553-558.

65. Wang, F. Research On Mechanism and application of BP neural network. Sci. Tech. Innov. Her. 2020, 17, $150-151$.

66. Geng, X.; Lu, S.; Jiang, M.; Sui, Q.; Lv, S.; Xiao, H.; Jia, Y.; Jia, L. Research on FBG-based CFRP structural damage identification using BP neural network. Photonic Sens. 2018, 8, 168-175. [CrossRef]

67. Jin, W.; Li, Z.J.; Wei, L.S.; Zhen, H. The improvements of BP neural network learning algorithm. In Proceedings of the WCC 2000-ICSP 2000, 2000 5th International Conference on Signal Processing Proceedings, 16th World Computer Congress 2000 , Beijing, China, 21-25 August 2000; pp. 1647-1649.

68. Zhang, Q.; Fu, X. A Neural Network Fuzzy Energy Management Strategy for Hybrid Electric Vehicles Based on Driving Cycle Recognition. Appl. Sci. 2020, 10, 696. [CrossRef]

69. Zhang, P.; Wu, X.; Du, C.; Xu, H.; Wang, H. Adaptive Equivalent Consumption Minimization Strategy for Hybrid Heavy-Duty Truck Based on Driving Condition Recognition and Parameter Optimization. Energies 2020, 13, 5407. [CrossRef]

70. Jiang, T. Research on Adaptive Equivalent Fuel Consumption Minimum Energy Management Strategy of PHEV Based on Driving Condition Recognition. Master's Thesis, Hefei University of Technology, Hefei, China, 2019.

71. Mohebali, B.; Tahmassebi, A.; Meyer-Baese, A.; Gandomi, A.H. Probabilistic neural networks: A brief overview of theory, implementation, and application. Handb. Probabilistic Models 2020, 347-367.

72. Wu, S.G.; Bao, F.S.; Xu, E.Y.; Wang, Y.-X.; Chang, Y.-F.; Xiang, Q.-L. A leaf recognition algorithm for plant classification using probabilistic neural network. In Proceedings of the 2007 IEEE International Symposium on Signal Processing and Information Technology, Giza, Egypt, 15-18 December 2018; pp. 11-16.

73. Wang, J.-S.; Chiang, W.-C.; Hsu, Y.-L.; Yang, Y.-T.C. ECG arrhythmia classification using a probabilistic neural network with a feature reduction method. Neurocomputing 2013, 116, 38-45. [CrossRef]

74. Li, L.-1.; Chen, K.; Gao, J.-m.; Li, H. Research on Quality Anomaly Recognition Method Based on Optimized Probabilistic Neural Network. Shock Vib. 2020, 2020, 6694732. [CrossRef]

75. Di, W.; Wang, M.; Sun, X.; Kang, F.; Xing, H.; Zheng, H.; Bian, J. Identification of rock bolt quality based on improved probabilistic neural network. Int. J. Model. Identif. Control 2018, 30, 105-117. [CrossRef]

76. $\mathrm{Hu}, \mathrm{J} . ; \mathrm{Hu}, \mathrm{Z} . ; \mathrm{Niu}, \mathrm{X}$.; Bai, Q. Research on energy management strategy considering battery life for plug-in hybrid electric vehicle. Adv. Mech. Eng. 2018, 10, 1687814018797766. [CrossRef]

77. Bai, Q. Study on Energy Management Strategy for Plug-in Hybrid Electrical Vehicle; Chongqing University: Chongqing, China, 2016.

78. Czabański, R.; Jeżewski, J.; Horoba, K.; Jeżewski, M. Fetal state assessment using fuzzy analysis of fetal heart rate signalsAgreement with the neonatal outcome. Biocybern. Biomed. Eng. 2013, 33, 145-155. [CrossRef]

79. Shukla, P.K.; Tripathi, S.P. On the design of interpretable evolutionary fuzzy systems (I-EFS) with improved accuracy. In Proceedings of the 2012 International Conference on Computing Sciences, Phagwara, India, 14-15 September 2012; pp. 11-14.

80. Cai, K.-Y.; Zhang, L. Fuzzy reasoning as a control problem. IEEE Trans. Fuzzy Syst. 2008, 16, 600-614.

81. Yang, S. Study on Driving Control Strategy For Plug-in Hybrid Electrical Vehicle Based on Mode Selection of Driver; Jilin University: Changchun, China, 2015.

82. Zhou, W. Research on Control Strategy of Plug-in Hybrid Electric Vehicle; Jiangsu University: Zhenjiang, China, 2017.

83. Cordero, J.; Aguilar, J.; Aguilar, K.; Chávez, D.; Puerto, E. Recognition of the driving style in vehicle drivers. Sensors 2020, 20, 2597. [CrossRef] [PubMed]

84. Saleh, M.; Aljaafreh, A.; Albdour, N. Fuzzy-based recognition model for driving styles. IJEECS Int. J. Electr. Electron. Comput. Syst. 2013, 16, 816-819.

85. Wu, H.; Li, Y.; Wu, C.; Ma, Z.; Zhou, H. A longitudinal minimum safety distance model based on driving intention and fuzzy reasoning. In Proceedings of the 2017 4th International Conference on Transportation Information and Safety (ICTIS), Banff, AB, Canada, 8-10 August 2017; pp. 158-162.

86. Karypis, G.; Han, E.; Kumar, V. A Hierarchical Clustering Algorithm Using Dynamic Modeling; Department of Computer Science and Engineering University of Minnesota: Minneapolis, MN, USA, 1999.

87. Ester, M.; Kriegel, H.-P.; Sander, J.; Xu, X. A density-based algorithm for discovering clusters in large spatial databases with noise. In Proceedings of the Second International Conference on Knowledge Discovery and Data Mining, Portland, OR, USA, 2-4 August 1996; pp. 226-231. 
88. Wang, W.; Yang, J.; Muntz, R. STING: A Statistical Information Grid Approach to Spatial Data Mining; Department of Computer Science, University of California: Los Angeles, CA, USA, 1997.

89. Lv, J.; Niu, L.; Qin, Z.; Zhou, Y.; Zhu, H. Driving Conditions Recognition and Parameters Optimization of Parallel HEVs. J. Anhui Uni. Technol.-Nat. Sci. 2018, 35, 232-239+255.

90. Liu, X. Instantaneous Optimal Control Strategy Based on a Variable Equivalent Factor for a Parallel Hybrid Electric Vehicle; Henan University Of Science And Technology: Luoyang, China, 2018.

91. Xie, H.; Tian, G.; Chen, H.; Wang, J.; Huang, Y. A distribution density-based methodology for driving data cluster analysis: A case study for an extended-range electric city bus. Pattern Recognit. 2018, 73, 131-143. [CrossRef]

92. Bu, G. Research of Energy Management Strategy for Plug-in Hybrid Electric Vehicles; Shandong University: Jinan, China, 2011.

93. Guo, G.; Wu, X.; Zhuo, S.; Xu, P.; Xu, G.; Cao, B. Prediction state of charge of Ni-MH battery pack using support vector machines for hybrid electric vehicles. In Proceedings of the 2008 IEEE Vehicle Power and Propulsion Conference, Harbin, China, 3-5 September 2008; pp. 1-4.

94. Smits, G.F.; Jordaan, E.M. Improved SVM regression using mixtures of kernels. In Proceedings of the 2002 International Joint Conference on Neural Networks; IJCNN'02 (Cat. No. 02CH37290), Honolulu, HI, USA, 12-17 May 2002; pp. $2785-2790$.

95. Zhang, X.; Wu, G.; Dong, Z.; Crawford, C. Embedded feature-selection support vector machine for driving pattern recognition. J. Frankl. Inst. 2015, 352, 669-685. [CrossRef]

96. Li, Y.; Chen, M.; Lu, X.; Zhao, W. Research on optimized GA-SVM vehicle speed prediction model based on driver-vehicle-roadtraffic system. Sci. China Technol. Sci. 2018, 61, 782-790. [CrossRef]

97. Zhang, Q. Research on Energy Optimization Management Strategy of Parallel Plug-In Hybrid Electric Vehicle; Yanshan University: Qinhuangdao, China, 2020.

98. Lu, G. The Study of Control Strategy for PHEV Based on Traveling Mileage Prediction; Jilin University: Changchun, China, 2017.

99. Hailong, G.; Yi, W. Study on HEV's driving condition recognition method based on PSO algorithm. J. Intell. Fuzzy Syst. 2018, 35, 87-98. [CrossRef]

100. Li, P.; Jiao, X.; Li, Y. Adaptive real-time energy management control strategy based on fuzzy inference system for plug-in hybrid electric vehicles. Control Eng. Pract. 2021, 107, 104703. [CrossRef]

101. Ivanco, A.; Colin, G.; Chamaillard, Y.; Charlet, A.; Higelin, P. Energy management strategies for a pneumatic-hybrid engine based on sliding window pattern recognition. Oil Gas Sci. Technol.—Rev. De L'institut Français Du Pétrole 2010, 65, 179-190. [CrossRef]

102. Yang, J.; Huang, X.; Tan, Y.; He, X. Forecast of driving load of hybrid electric vehicles by using discrete cosine transform and support vector machine. In Proceedings of the 2008 IEEE International Joint Conference on Neural Networks (IEEE World Congress on Computational Intelligence), Hong Kong, 1-8 June 2008; pp. 2227-2234.

103. Gao, J.; Zhu, H.; Murphey, Y.L. Adaptive Window Size Based Deep Neural Network for Driving Maneuver Prediction. In Proceedings of the 2020 Chinese Control And Decision Conference (CCDC), Hefei, China, 22-24 August 2020; pp. 87-92.

104. Lin, Y.; Wang, P.; Ma, M. Intelligent transportation system (ITS): Concept, challenge and opportunity. In Proceedings of the 2017 IEEE 3rd International Conference on Big Data Security on Cloud (Bigdatasecurity), IEEE International Conference on High Performance and Smart Computing (HPSC), and IEEE International Conference on Intelligent Data and Security (IDS), Beijing, China, 26-28 May 2017; pp. 167-172.

105. Sumalee, A.; Ho, H.W. Smarter and more connected: Future intelligent transportation system. Iatss Res. 2018, 42, 67-71. [CrossRef]

106. Vanajakshi, L.; Subramanian, S.C.; Sivanandan, R. Travel time prediction under heterogeneous traffic conditions using global positioning system data from buses. IET Intell. Transp. Syst. 2009, 3, 1-9. [CrossRef]

107. Qian, T.; Shao, C.; Wang, X.; Shahidehpour, M. Deep reinforcement learning for EV charging navigation by coordinating smart grid and intelligent transportation system. IEEE Trans. Smart Grid 2019, 11, 1714-1723. [CrossRef]

108. Fu, J.; Yang, R.; Li, X.; Sun, X.; Li, Y.; Liu, Z.; Zhang, Y.; Sunden, B. Application of artificial neural network to forecast engine performance and emissions of a spark ignition engine. Appl. Therm. Eng. 2022, 201, 117749. [CrossRef]

109. da Silva, S.F.; Eckert, J.J.; Silva, F.L.; Silva, L.C.; Dedini, F.G. Multi-objective optimization design and control of plug-in hybrid electric vehicle powertrain for minimization of energy consumption, exhaust emissions and battery degradation. Energy Convers. Manag. 2021, 234, 113909. [CrossRef]

110. Gunantara, N. A review of multi-objective optimization: Methods and its applications. Cogent Eng. 2018, 5, 1502242. [CrossRef] 